\title{
A case of arrhythmogenic right ventricular cardiomyopathy
}

\author{
Sorel Goland MD ${ }^{1}$, Lawrence SC Czer MD ${ }^{1}$, Daniel Luthringer $\mathrm{MD}^{2}$, Robert J Siegel MD ${ }^{1}$
}

S Goland, LSC Czer, D Luthringer, RJ Siegel. A case of arrhythmogenic right ventricular cardiomyopathy. Can J Cardiol 2008;24(1):61-62.

The present report describes a 40-year-old woman with a long history of monomorphic ventricular tachycardia and left bundle branch block. She was treated with various antiarrhythmic agents; ventricular tachycardia ablation was attempted and an automatic implantable cardioverter defibrillator was implanted. Three-dimensional echocardiography clearly demonstrated features of arrhythmogenic right ventricular cardiomyopathy, including marked right ventricular (RV) dilation, decreased RV systolic function and thinning of the RV free wall. Other RV morphological abnormalities included excessive trabeculations and a localized apical aneurysm. Two years later, the patient developed symptoms of congestive heart failure. Despite maximal medical therapy, her clinical condition continued to deteriorate and she was referred for heart transplantation. Results of the pathology of her explanted heart confirmed this rare diagnosis. She presented with an unusual clinical course for arrhythmogenic right ventricular cardiomyopathy, which was complicated by progressive congestive heart failure and ultimately required heart transplantation. Threedimensional echocardiography identified the structural abnormalities related to this rare disease.

Key Words: Arrhythmia; Cardiomyopathy; Right ventricle

\section{Un cas de myocardiopathie arythmogène du ventricule droit}

Le présent rapport décrit le cas d'une femme de 40 ans ayant une longue histoire de tachycardie ventriculaire monomorphe et de bloc de branche gauche. Elle a été traitée au moyen de divers antiarythmiques. On a tenté une ablation de la tachycardie et implanté un défibrillateur à synchronisation automatique. L'échocardiographie tridimensionnelle démontrait clairement des caractéristiques de myocardiopathie arythmogène du ventricule droit, y compris une dilatation du ventricule droit (VR) marquée, une diminution de la fonction systolique du VR et un amincissement de la paroi libre du VR. La patiente présentait d'autres anomalies morphologiques du VR, y compris des trabéculations excessives et un anévrisme apical localisé. Deux ans plus tard, la patiente a développé des symptômes d'insuffisance cardiaque congestive. Malgré une médicothérapie maximale, son état clinique a continué de se détériorer, et elle a été aiguillée vers une transplantation cardiaque. Les résultats de la pathologie du cœur explanté ont confirmé ce diagnostic rare. Elle présentait une évolution clinique inhabituelle de myocardiopathie arythmogène du ventricule droit, compliquée par une insuffisance cardiaque congestive progressive et a finalement dû subir une transplantation cardiaque. L'échocardiographie tridimensionnelle a permis de repérer les anomalies structurelles reliées à cette maladie rare.

40-year-old woman had a history of recurrent attacks of rapid A palpitations associated with dizziness since she was 19 years of age. Subsequently, she was found to have monomorphic ventricular tachycardia with left bundle branch block morphology and a normal QRS axis. Her 12-lead electrocardiogram, in sinus rhythm, showed inverted $\mathrm{T}$ waves in leads V1 and V2. Echocardiography showed severe dilation of the right ventricle (RV), with depressed RV systolic function and moderate tricuspid valve regurgitation. Left ventricular size and function were normal. Three-dimensional echocardiography was performed to better assess RV morphology (Figures 1 and 2) and demonstrated marked RV dilation, decreased RV systolic function and thinning of the RV free wall. Other RV morphological abnormalities included excessive trabeculations and a localized apical aneurysm. The patient was diagnosed as having arrhythmogenic RV cardiomyopathy (ARVC). She was treated with various antiarrhythmic agents; ventricular tachycardia ablation was attempted and an automatic implantable cardioverter defibrillator was implanted. She remained stable for two years, but then developed weakness and shortness of breath on exertion. A cardiopulmonary exercise test showed a maximal oxygen consumption of $18 \mathrm{~mL} / \mathrm{kg} / \mathrm{min}$. The patient's symptoms, including severe weakness, shortness of breath on minimal exertion and weight loss, progressed with worsened congestive heart failure. A repeat cardiopulmonary exercise test showed a reduction in maximal oxygen consumption to $13 \mathrm{~mL} / \mathrm{kg} / \mathrm{min}$. Despite maximal medical therapy, her clinical condition continued to deteriorate and she underwent heart

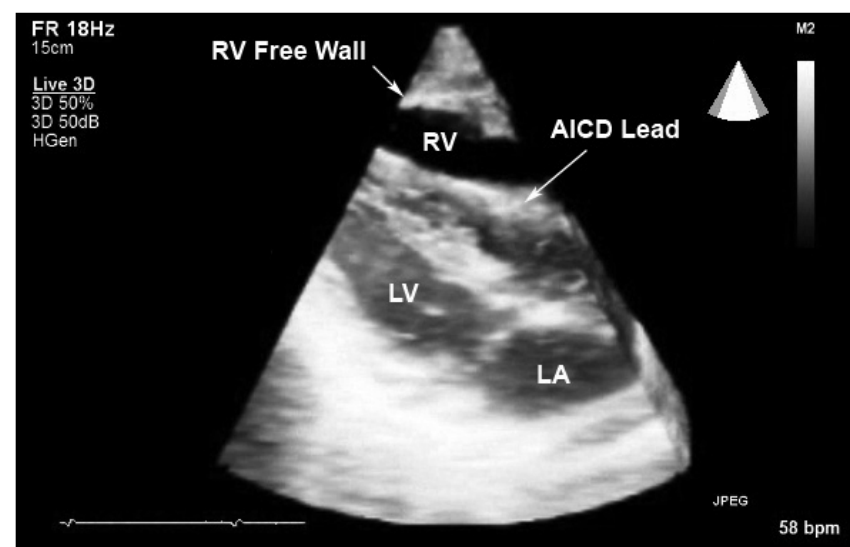

Figure 1) Real-time three-dimensional image (view online at www.pulsus.com) in the modified parasternal long-axis view showing marked dilation of the right ventricle $(R V)$ and thinning of the RV free wall. The automatic implantable cardioverter defibrillator (AICD) lead can be seen in the RV. The free wall appeared to be thinner than the lead. LA Left atrium; LV Left ventricle

transplantation. The explanted heart demonstrated findings consistent with ARVC (Figures 3A and 3B).

${ }^{1}$ Division of Cardiology; ${ }^{2}$ Division of Pathology, Cedars-Sinai Medical Center, Los Angeles, California, and David Geffen School of Medicine,

University of California, Los Angeles, California, USA

Correspondence: Dr Robert J Siegel, Cedars-Sinai Medical Center, 8700 Beverly Boulevard, Room 5623, Los Angeles, California 90048, USA.

Telephone 310-423-3849, fax 310-278-7591, e-mail siegel@cshs.org

Received for publication July 31, 2006. Accepted August 20, 2006 


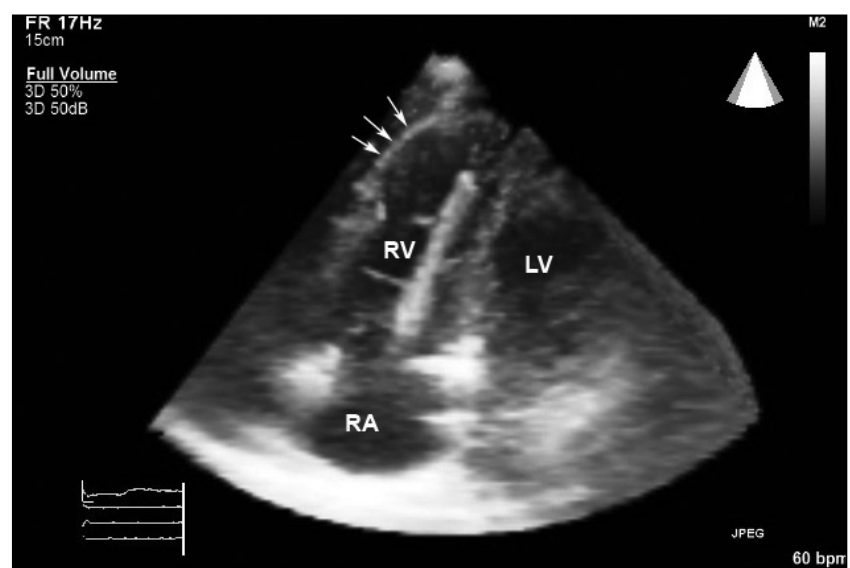

Figure 2) Real-time three-dimensional echocardiography (view online at www.pulsus.com) using the 'full-volume' mode, which consists of the acquisition of a large single pyramid of data $\left(120^{\circ} \times 60^{\circ}\right)$ recorded during four consecutive cardiac cycles. Severe dilation of the right ventricle (RV), thinning of the RV free wall, excessive trabeculations and a large apical aneurysm are shown (arrows). The automatic implantable cardioverter defibrillator lead can be seen in the RV. LV Left ventricle; RA Right atrium

ARVC is a disease of unknown cause that is characterized by fibrofatty replacement of the RV myocardium. It occurs in both sporadic and familial forms. ARVC is characterized by RV dysfunction and fatal ventricular arrhythmias $(1,2)$. The clinical diagnosis of ARVC is often difficult because of the nonspecific nature of disease features, as well as the broad spectrum of phenotypic manifestations. The diagnosis of ARVC is currently based on the presence of major and minor criteria encompassing electrocardiographic, arrhythmic, RV morphofunctional, histopathological and clinical genetic factors (3). The molecular biology has provided new insights in understanding the pathophysiology of ARVC, showing that it is a desmosomal disease resulting from defective cell adhesion proteins. Two recent reports $(4,5)$ showed that PKP2 gene mutations are found in more than $40 \%$ of ARVC patients.

Evaluation of the heart by one of the common imaging modalities is an integral part of the diagnostic workup, serving both to identify the morphological features of ARVC and to exclude other causes of heart disease. Structural abnormalities may be localized, in the form of patchy wall thinning and segmental dilation, or diffuse, with global dilation of the RV. Functional impairment ranges from mild regional wall motion abnormalities to generalized hypokinesia. Although cardiac magnetic resonance imaging is not restricted by acoustic windows and offers the added advantage of noninvasive tissue characterization, echocardiography has the benefit of being inexpensive and readily available. Echocardiography is widely used to evaluate RV structural abnormalities, but the diagnosis of ARVC still remains challenging. Visualization of the RV by echocardiography is not always satisfactory, and may be partially be enhanced by the use of intravenous saline contrast alone. Real-time, three-dimensional echocardiography can be used for more accurate assessment RV morphology and function.

The clinical course of ARV dysplasia is variable. The most recent report with a large series of patients with ARV dysplasia (6) demonstrated that one-half of patients with ARVC who presented with a malignant or potentially malignant ventricular arrhythmia had an

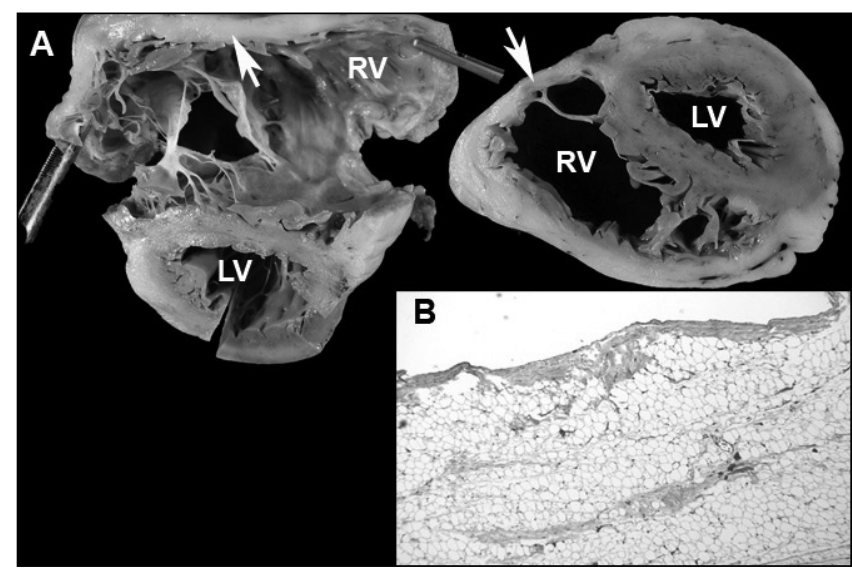

Figure 3) A Gross photographs demonstrating right ventricular (RV) dilation, with extensive fatty replacement primarily involving the lateral (free) wall. The wall is thinned in areas, with virtually complete absence of myocardium in some areas (arrows). B Microscopic examination confirmed the loss of myocardium, demonstrating replacement by mature fatty tissue. This focally extended from the endocardial through the epicardial aspects of the RV. LV Left ventricle

excellent prognosis, once treated with an implantable cardioverter defibrillator. Although RV dysfunction is present, clinically significant heart failure is seen only in a minority of patients. Progression to heart failure is uncommon and occurs in fewer than $10 \%$ of patients. In the report by Dalal et al (5), only one patient progressed from right heart failure to a biventricular heart failure and subsequently died while awaiting a heart transplant. End-stage heart failure leading to heart transplantation is extremely rare and reported in this study in only two of 100 patients with ARVC.

We present an unusual case of ARVC complicated by progressive congestive heart failure, which ultimately required heart transplantation. Three-dimensional echocardiography was useful in clearly identifying the structural abnormalities related to this rare disease.

\section{REFERENCES}

1. Thiene G, Nava A, Corrado D, Rossi L, Pennelli N. Right ventricular cardiomyopathy and sudden death in young people. N Engl J Med 1988;318:129-33.

2. Gemayel C, Pelliccia A, Thompson PD. Arrhythmogenic right ventricular cardiomyopathy. J Am Coll Cardiol 2001;38:1773-81

3. Corrado D, Fontaine G, Marcus FI, et al. Arrhythmogenic right ventricular dysplasia/cardiomyopathy: Need for an international registry. Study Group on Arrhythmogenic Right Ventricular Dysplasia/Cardiomyopathy of the Working Groups on Myocardial and Pericardial Disease and Arrhythmias of the European Society of Cardiology and of the Scientific Council on Cardiomyopathie of the World Heart Federation. Circulation 2000;101:E101-6.

4. van Tintelen JP, Entius MM, Bhuivan ZA, et al. Plakophilin-2 mutations are the major determinant of familial arrhythmogenic right ventricular dysplasia/cardiomyopathy. Circulation 2006;113:1650-8

5. Dalal D, Molin LH, Piccini J, et al. Clinical features of arrhythmogenic right ventricular dysplasia/cardiomyopathy associated with mutations in plakophilin-2. Circulation 2006;113:1641-9.

6. Dalal D, Nasir K, Bomma C, et al. Arrhythmogenic right ventricular dysplasia: A United States experience. Circulation 2005; $112: 3823-32$ 